O.G. male.-The next was a moderate myope. The spectacle correction which gave $6 / 5$ partly in each eye was :-

$$
\text { R.E. } \frac{\mathrm{sph}-6.0}{\mathrm{cyl}-0.50} \quad y \quad \text { L.E. } \frac{\mathrm{sph}-5.50}{\mathrm{cyl}-1.0} \leftarrow
$$

With a spherical contact lens $-3.50 \mathrm{D}$ each eye read $6 / 6$, but with a sphero-cylindrical one

$$
\text { R.E. } \frac{\mathrm{sph}-3.0}{\mathrm{cyl}-1.0} \searrow 100 \quad \text { L.E. } \frac{\mathrm{sph}-3.0}{\mathrm{cyl}-1.0} \swarrow_{80}
$$

each eye could read $6 / 5$.

The third patient, M. R. (male), was referred to the Contact Lens Centre by Mr. Myles Bickerton to whom we are indebted for permission to refer to the case. The right eye with spectacle lens saw $6 / 5$, but the left was amblyopic. With a spherical contact lens $+30 \mathrm{D}$ each eye, the right would not improve to beyond $6 / 6$, and the amblyopic left eye saw 6/24. With a sphero-cylindrical contact lens $\frac{\mathrm{sph}+2.75}{\mathrm{cyl}+0.7510} \measuredangle$ the right eye saw $6 / 5$.

The fourth case, Mr. O. aged 19 years, was one of conical cornea. This patient was a West Indian. He developed a small amount of myopia about four years ago and this increased steadily. He was diagnosed in Jamaica as early conical cornea and proceeded to England to obtain contact lenses. With spectacles (concave sphero-cylinders) he could read 6/12 with the right eye, and $6 / 6$ partly with the left, but complained that, although he could see the letters, they had double outlines, which worried him all the time. With a spherical contact lens he read 6/9 R.E. and $6 / 6$ partly L.E. practically the same as with his glasses. By adding a 2.5 cylinder to the back of the contact lens of his left eye, he read $6 / 5$ easily, and all the double outlines disappeared. The right eye was not improved, but he stated that he thought the visual acuity in this eye had always been less than in the left.

\title{
ANNOTATION
}

\section{The Leeds Reading Aid for Partially Sighted Children}

The Report of the School Medical Officer (Dr. St. Clair Stockwell) for the year ended December 31,1938, in the City of Leeds, contains many items of importance. To ophthalmologists Appendix B, which deals with the subject of our heading, is of great interest. In an historical retrospect we are told that a class for partially blind (now 
termed partially sighted) children was formed at Leeds in 1911 and there were enough children of this type to form two classes. In 1917 reorganisation for the admission of myopes was undertaken and for some years there were two classes for the partially blind and one for myopes. The first class was allowed to use books of good type but the myopes none at all. All writing was done with white chalk or crayon on a black surface. Children, whose sight the ophthalmic surgeon considered "very bad" were placed in classes with blind children and taught on blind lines. The results were not altogether satisfactory. The Report on the education of partially sighted $(193 t)$ showed that nearly all these children would have to earn their living in sighted occupations and advised that they should be taught on sighted lines.

A great deal of preliıninary work was done by Mr. Lodge and Mr. Harry Lee to improve matters and a device has been perfected for allowing magnification of the print by a glass. The lens used is $+3.5 \mathrm{D}$. plano-sphere, the plane as the under surface. It is made in an oblong block measuring $6 \frac{1}{2}$ ins. by $3 \frac{1}{4}$ ins. and has a rigid frame which is attached to the desk. A linear magnification of 2 is thus given, the glass is wide enough to cover the page of most books and the height gives a sufficient length of the page for most readers. A cowl for a lamp is built into the top part of the frame and acts as a reflector.

Research in illumination has shown that an amber tint is best for myopes and a pale flesh tint for other partially sighted children.

A 20-watt bulb gives best illumination for myopes and a 25-watt bulb for partially sighted. "A rheostat control would decide the most suitable intensity for the few abnormal cases."

Twenty-nine myopes have been using the aid for the 12 months covered by the Report.

Regular examination of these are shown :

1 (a) Number showing no increase either before or since using 5

(b) " " , increase before but none since using - 16

(c) " " $\quad$ increase before and since - - - 4

(N.B.- - These children in the first three items of the schedule have been under observation for periods varying from three to nine years.)

(d) Number whose progress before using was unknown - 4

2 (a) Number showing no increase since using - - $\quad 24$

(b) ", ", increase since using - - - 4

(c) Not finally estimated (in Hospital) - - $\quad$ - 1

The authors of the Report claim that there is no doubt that the aid has been of benefit in education, and the children like the aid.

It is to be hoped that other educational authorities will adopt the Leeds aid and we feel that the device is likely to be of great assistance and that Leeds deserves congratulations for this research and the results. 